\title{
EVALUASI PENERAPAN KESELAMATAN DAN KESEHATAN KERJA (K3) PADA PRAKTIK FINISHING BANGUNAN SMK NEGERI 2 YOGYAKARTA
}

\author{
Monica Erfian', dan Nuryadin Eko Raharjo ${ }^{2}$ \\ 1,2, Pendidikan Teknik Sipil dan Perencanaan, FT, UNY \\ Email: nuryadin_er@uny.ac.id
}

\begin{abstract}
ABSTRAK
Penelitian ini bertujuan untuk mengetahui: (1) antecedents (input), transcription (process), danoutput (hasil) dari penerapan Keselamatan dan Kesehatan Kerja (K3) di SMK Negeri 2 Yogy akarta pada praktikfinishing bangunan, (2) pemahaman sis wa terhadap penerapan K3 dibengkel Kompetensi Keahlian Konstruksi Gedung Sanitasi dan Perawatan (KGSP). Metode evaluasi yang digunakan adalah Countenance Stake dengan3tahapan meliputi antecedents (input), trans cription (process), dan output. Subyek penelitian adalah sis wa kelas XIKGSP SMK Negeri 2 Yogyakarta. Obyek penelitian adalah penerapan Keselamatan dan Kesehatan Kerja (K3). Data dikumpulkan melalui wawancara, pengamatan, dan dokumentasi. Data di analis is secara deskriptif. Hasil penelitian iniadalah:(1) antecedents (in put) penerapan K3 pada praktik finish ing bangun andalamaspekkesiapan guru dan sis wa sudah baik, ditinjau dari penetapan dasar hukum dan perencanaan K3 sudah terlaksana. (2) transcription (process) penerapan K3 pada praktik finishing bangunan telah berjalan dengan baik dilihat dari persentase penerapan K3 sebanyak 96\%. (3) output penerapan K3 pada praktik finishing bangunan ditinjaudari hasil Pemantauan dan evaluasi kinerja K3 yang dicapai sudah baik.
\end{abstract}

Kata kunci: Evaluasi countenance stake, Penerapan K3, Finishing bangunan

\section{ABSTRACT}

This study aims to determine: (1) the antecedents (input), transcription(process), andoutput(results) of the application of Occupational Safety and Health (K3) at SMK Negeri 2 Yogyakarta on buildingfinishing practices, (2) students' understanding of the application of $K 3$ in the Building ConstructionSanitationand Care $(K G S P)$. The evaluation method use Countenance Stake with 3 stages including antecedents(input), transcription (process), and output. The research subjects were students of class XI KGSP SMK Negeri 2 Yogyakarta. The research object is the application of occupational safety and health (K3). Datawerecollected throughinterviews, observations, and documentation. The data were analyzed descriptively. The results of this study are: (1) antecedents (input) of the application of $\mathrm{K} 3$ in building finishing practices in the aspectsofteacherandstudent readiness, in terms oflegal basis determination and $K 3$ planning has been implemented. (2) the transcription (process) ofK3 application in building finishing practices has been running well, seenfromthepercentageofK3 application of $96 \%$. (3) the output of 33 application in building finishing practices isreviewedfromtheresultsof monitoring and evaluation of $K 3$ performance that have been achieved.

Keywords: Evaluation of stake countenance, Implementation of K3, Building finishing

\section{PENDAHULUAN}

Sekolah menengah kejuruan merupakan salah satu implementasi dari pendidikan menengah kejuruan di Indonesia, dimana peserta didiknya diarahkan agar menguasai bidang keahlian tertentu yang tentunya sesuai dengan tujuan SMK itu sendiri adalah menyiapkan peserta didiknya untuk siap bekerja. SMK
Negeri 2 Yogyakarta adalah salah satu sekolah kejuruan ternama di Daerah Istimewa Yogyakarta yang memiliki berbagai kompetensi bidang keahlian dengan lulusan yang berkualitas dan siap masuk ke dunia kerja.

Peserta didik dari sekolah menengah kejuruan akan selalu berhubungan dengan masalah keselamatan dan kesehatan kerja (k3) baik di bengkel 
pada saat pembelajaran praktik maupun di dunia industri. Menurut Peraturan Menteri Tenaga Kerja RI No. PER.03/MEN/1998 menjelaskan tentang kecelakaan kerja merupakan suatu kejadian yang tidak dikehendaki maupun tidak diduga yang dapat menimbulkan korban manusia atau harta benda karena setiap kecelakaan yang tidak diharapkan pasti disertai kerugian material ataupun penderitaan dari yang paling ringan sampai yang paling berat.

Keselamatan dan Kesehatan Kerja (K3) merupakan tugas untuk semua orang yang bekerja dan juga pada siswa ketika melaksanakan praktik di bengkel. Siswa merupakan aset yang paling berharga bagi sekolah. Agar siswa dapat melaksanakan pekerjaan praktik dengan aman dan produktif, maka setiap siswa harus waspada dan berusaha agar dalam keadaan selamat dan sehat dalam melaksanakan pekerjaan.

\section{Mengingat}

pentingnya

Keselamatan dan Kesehatan Kerja para praktikan, maka untuk mengantisipasi dan mengurangi angka kecelakaan kerja serta penyakit akibat kerja juga untuk melindungi praktikan atau tenaga kerja. Oleh karena itu Undang-undang No.13 Tahun 2003 tentang Ketenagakerjaan disebutkan bahwa Pasal 86 Ayat 1 dan 2 yang setiap pekerja mempunyai hak untuk memperoleh perlindungan atas keselamatan kesehatan kerja, moral dan kesusilaan, perlakuan yang sesuai dengan martabat manusia serta nilai-nilai agama, untuk melindungi keselamatan pekerja/buruh guna mewujudkan produktivitas kerja yang optimal.

Keselamatan dan kesehatan kerja tidak hanya mengarah di perusahaan saja melainkan juga di sebuah lembaga pendidikan juga penting terutama keselamatan dan kesehatan kerja dalam melakukan sebuah praktik pelajaran. Pengetahuan menganai keselamatan dan kesehatan kerja yang diajarkan oleh guru di sekolah adalah untuk menjaga keselamatan dan kesehatan siswa pada saat bekerja di sekolah maupun di dalam dunia industri dan menghindarkan siswa terhadap resiko kecelakaan kerja yang mugkin terjadi. Maka setiap tempat kerja hendaknya perlu menerapkan keselamatan dan kesehatan kerja terutama di sekolah menengah kejuruan, khususnya dalam praktik siswa yang nantinya akan berhadapan langsung dengan bahan, peralatan, dan perlengkapan kerja yang memiliki potensi bahaya.

Di SMK Negeri 2 Yogyakarta khususnya Kompetensi Keahlian Konstruksi Gedung Sanitasi dan Perawatan (KGSP), pendidikan tentang Keselamatan dan Kesehatan Kerja (K3) tidak diberikan secara langsung kepada siswa dalam bentuk mata pelajaran, melainkan siswa mendapatkan pendidikan tentang $\mathrm{K} 3$ pada saat mata pelajaran praktikum. Seharusnya hal ini membuat siswa terbiasa dengan perilaku K3 selama menjalani praktik di bengkel. Pentingnya penelitian tentang penerapan K3 dalam praktik siswa sebagai upaya pencegahan berbagai potensi bahaya. Penerapan K3 di sekolah perlu dilakukan karena SMK merupakan salah satu lembaga pendidikan yang banyak mencetak lulusan yang siap bekerja, sehingga diharapkan nantinya dapat dijadikan bekal untuk siswa dalam menjaga K3 apabila mereka bekerja pada sebuah perusahaan.

Untuk mencapai K3 yang baik, semua pihak yang bekerja didalam bengkel perlu menerapkan budaya K3 dalam praktik sehari-hari dan kesadaran untuk perperilaku K3 harus ditanamkan sejak dini. Melalui 
kegiatan praktik di bengkel maupun di industri adalah salah satu sarana untuk memperkenalkan dan menanamkan kesadaran siswa dalam berperilaku K3. Mengingat dunia kerja Teknik Sipil merupakan lingkungan kerja dengan tingkat resiko bahaya yang tinggi. Permasalahan yang terjadi adalah sampai saaat ini belum pernah dilakukan evaluai penerapan K3 di kompetensi KGSP SMKN 2 Yogyakarta. Oleh karena itu perlu dilakukan penelitian evaluasi yang mencakup input, proses, dan hasil pelaksanaan K3 khususnya pada mata pelajaran praktik finishing bangunan.

Keselamatan kerja pada dasarnya adalah kebutuhan setiap manusia yang menjadi naluri dari setiap makhluk hidup. Dengan secara tidak sadar mereka telah mengenal aspek keselamatan untuk mengantisipasi berbagai bahaya di sekitar lingkungan hidupnya. Di abad modern ini, aspek keselamatan telah menjadi tuntutan dan kebutuhan umum. Walaupun keselamatan telah menjadi kebutuhan, namun dalam kenyataannya manusia masih mengabaikan keselamatan (Soehatman, 2010: 6-7).

Menurut Buntarto (2015: 1), keselamatan kerja adalah suatu keadaan yang terhindar dari bahaya selama melakukan pekerjaan. Keselamatan kerja juga merupakan salah satu faktor yang harus dilakukan selama bekerja. Tidak ada seseorang di dunia ini yang menginginkan terjadinya kecelakaan. Keselamatan kerja sangat bergantung pada jenis, bentuk, dan lingkungan dimana pekerjaan itu dilaksanakan maupun dikerjakan. Menurut Irzal (2016: 13), keselamatan kerja adalah keselamatan yang berhubungan dengan mesin, alat kerja, bahan dan proses pengolahannya, lingkungan tempat kerja, serta cara-cara melakukan pekerjaan.
Keselamatan kerja juga sebagai suatu usaha untuk menciptakan lingkungan kerja yang aman, agar dapat mencegah semua bentuk kecelakaan yang mungkin terjadi.

Unsur-unsur penunjang keselamatan kerja menurut Buntarto (2015: 1) adalah sebagai berikut: (1) Adanya unsur-unsur keamanan dan kesehatan kerja, (2) Adanya kesadaran dalam menjaga keamanan dan kesehatan kerja, (3) Teliti dalam bekerja, (4) Melaksanakan prosedur kerja dengan memperhatikan keamanan dan kesehatan kerja. Sedangkan unsur-unsur penunjang keamanan yang bersifat non material sebagai berikut: (1) buku petunjuk penggunaan alat/buku manual, (2) rambu-rambu dan isyarat bahaya, (3) himbauan-himbauan, (4) petugas keamanan.

Lebih lanjut Buntarto (2015: 4) menjelaskan bahwa kesehatan kerja merupakan suatu kondisi kesehatan yang bertujuan agar masyarakat pekerja dapat memperoleh derajat kesehatan yang setinggi-tingginya, baik jasmani, rohani, maupun sosial, dengan usaha pencegahan dan pengobatan terhadap penyakit atau gangguan kesehatan yang disebabkan oleh pekerjaan, lingkungan kerja maupun penyakit umum. Kesehatan kerja menurut (Kuswana, 2014, hal. 23), adalah suatu keadaan seorang pekerja yang terbebas dari gangguan fisik maupun mental sebagai akibat pengaruh interaksi pekerjaan dan lingkungannya, serta penerapannya untuk menjamin keutuhan dan kesempurnaan tenaga kerja baik jasmani maupun rohani.

Sementara itu kesehatan dan keselamatan kerja (K3) adalah salah satu bentuk upaya untuk menciptakan tempat kerja yang aman, sehat, bebas dari pencemaran lingkungan, sehingga dapat melindungi dan bebas dari kecelakaan kerja, serta dapat meningkatkan efisiensi dan 
produktivitas kerja (Irzal, 2016). Kesehatan dan keselamatan kerja merupakan hal yang tidak terpisahkan dalam sistem ketenagakerjaan dan sumber daya manusia. Keselamatan dan kesehatan kerja berdampak positif dalam keberlanjutan produktivitas kerjanya. Oleh sebab itu, isu keselamatan dan kesehatan kerja pada saat ini bukan sekedar kewajiban yang harus diperhatikan oleh para pekerja, akan tetapi juga harus dipenuhi oleh sebuah sistem pekerjaan. Pada saat ini keselamatan dan kesehatan kerja bukan semata sebagai kewajiban, akan tetapi sudah menjadi kebutuhan untuk para pekerja dan untuk setiap bentuk kegiatan pekerjaan. Perusahaan maupun lembaga penyelenggara pendidikan kejuruan juga perlu melaksanakan program keselamatan dan kesehatan kerja (K3) yang diharapkan dapat menurunkan tingkat kecelakaan kerja. Sedangkan kesehatan dan keselamatan kerja menurut (Kuswana, 2015, hal. 60) adalah sebagai salah satu persyaratan dalam melaksanakan tugas dan suatu bentuk faktor hak asasi setiap pekerja.

K3 sangat penting untuk diterapkan karena K3 salah satu ketentuan perundangan dan memilki landasan hukum yang wajib dipatuhi untuk melindungi hak pekerja akibat kecelakaan kerja. Menurut (Ramli, 2010, hal. 11-12) di Indonesia juga memiliki dasar hukum K3, berikut diantaranya adalah 1) Undang-undang No. 1 tahun 1970 tentang keselamatan kerja yang diberlakukan pada tanggal 12 Januari 1970. Dalam undangundang ini memuat tentang persyaratan keselamatan kerja mengenai kewajiban dan hak setiap tenaga kerja; 2) Undang-undang No. 13 tahun 2003 tentang ketenagakerjaan. Dalam undang-undang ini memuat tentang keselamatan kerja pada pasal 86 bahwa setiap bengkel wajib menerapkan K3 untuk melindungi tenaga kerja yang sedang beroperasi di bengkel. Sedangkan pada pasal 87 mewajibkan setiap manajemen bengkel untuk menerapkan K3 yang terintegrasi dengan manajemen lainnya; dan 3) Undangundang No. 8 tahun 1999 tentang perlindungan konsumen pada pasal 2 menyebutkan bahwa perlindungan berdasarkan keamanan dan keselamatan konsumen. Sedangkan pada pasal 4 mengenai aspek keselamatan konsumen dan keselamatan produk.

\section{METODE}

Penelitian ini menggunakan metode evaluasi Countenance Stake. Dalam penelitian ini metode Countenance Stake terdapat 3 tahapan yang dilakukan diantaranya adalah antecedents (masukan), transcription (proses), dan output (keluaran). Pendekatan yang digunakan yaitu pendekatan deskriptif merupakan penelitian yang tidak menguji hipotesis tetapi hanya menggambarkan seperti apa adanya tentang suatu variabel, gejala atau keadaan. Penelitian ini termasuk penelitian dengan data kuantitatif sehingga dapat menghasilkan angka yang berdasarkan jenis dan teknik analisis yang digunakan.

Penelitian ini mengguakan model evaluasi Countenance Stake dan model ini dibagi menjadi 3 tahapan yaitu Antecedents (input), Transaction (proses) dan Output dengan mengambil responden siswa kelas XI KGSP SMK Negeri 2 Yogyakarta yang beralamat di jalan AM Sangaji No.47 Cokrodiningratan Jetis Yogyakarta. Pengambilan data dilakukan dengan teknik observasi, dokumentasi, dan wawancara.

Teknik analisis data yang digunakan untuk data observasi dokumentasi berupa dokumentasi sarana dan prasarana bengkel 
Evaluasi Penerapan ... (Monica/ hal. 139-148)

serta perlengkapan K3 untuk membandingkan dengan SOP yang berlaku.

Tabel 1. Pers entase K3 oleh Guru

\begin{tabular}{ccc}
\hline No. & $\begin{array}{c}\text { Persentase } \\
\text { Penerapan }\end{array}$ & Kategori \\
\hline 1. & $>80-100$ & Baik \\
\hline 2. & $>60-80$ & Cukup \\
\hline 3. & $>40-60$ & Kurang Baik \\
\hline 4. & $>20-40$ & Tidak Baik \\
\hline 5. & $0-20$ & Sangat Tidak Baik \\
\hline
\end{tabular}

\section{HASIL DAN PEMBAHASAN}

\section{Antecedents (Input)}

Tahapan ini memiliki 2 indikator yaitu penetapan dasar hukum K3 dan Perencanaan K3. Penetapan dasar hukum K3 finishing bangunan di SMK Negeri 2 Yogyakarta menggunakan undang-undang Nomor 1 tahun 1970 tentang K3 dan SKB MENAKER \& PU Nomor 174/104/86 tentang K3 Konstruksi.

Perencanaan K3 pada finishing bangunan memiliki sub indikator yaitu P3K, identifikasi bahaya, lingkungan kerja, dan peralatan kerja. Berikut adalah hasil penelitian objek dari indikator perencanaan K3:

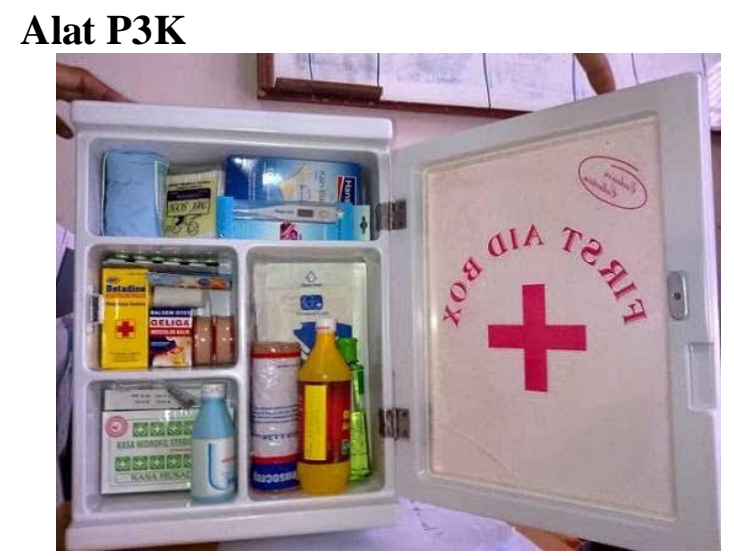

Gambar 1. Alat P3K

Alat P3K yang tersedia di bengkel batu SMK Negeri 2 Yogyakarta berupa betadin, handsaplas, plester, kasa, alkohol, revanol, mintak tawon, minyak kayu putih, perban, dan kapas.

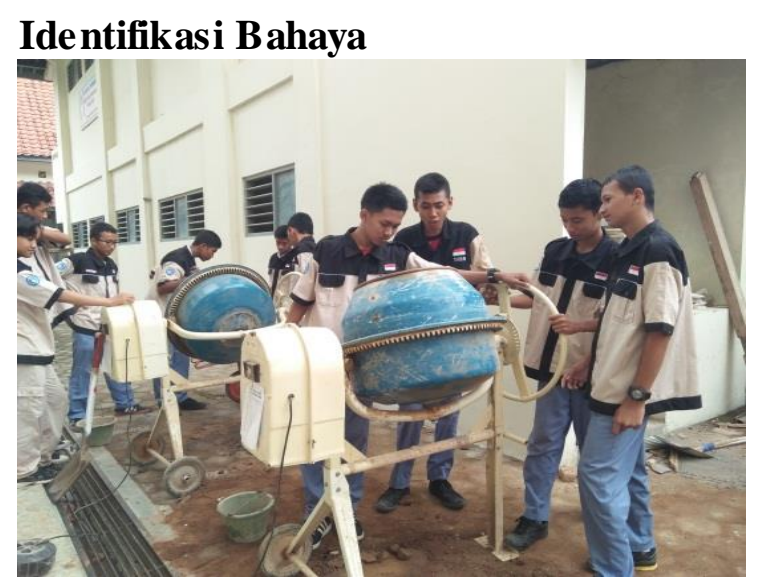

Gambar 2. Identifikasi Bahaya

Identifikasi bahaya yang mungkin terjadi di bengkel batu SMK Negeri 2 Yogyakarta sebagai berikut: (1) Bahaya pada penggunaan mesin seperti tangan bisa terpotong atau terjepit jika tidak menggunakan APD yang sesuai dengan prosedur. (2) Bahaya pada penggunaan peralatan berupa tangan bisa terpukul palu atau kaki terkena cankul jika tidak menggunakan APD dengan benar dan peralatan bisa rusak jika tidak digunakan sesuai dengan fungsinya. (3) Bahaya pada penggunaan bahan seperti pasir yang rawan masuk kemata dan debu semen bisa mengganggu pernafasan jika tidak menggunaka masker atau APD yang sesuai. (4) Jenis kecelakaan yang bisa terjadi pada saat praktik di bengkel seperti tangan terpotong, terjepit, terkena alat circle, kaki tertusuk paku jika tidak berhati-hati dalam praktik dan tidak menggunakan APD yang sesuai dengan SOP. (5) Kecelakaan akibat kerja bisa berupa infeksi pernafasan karena terhirup debu semen pada saat praktik, berdarah karena terluka pada saat menggunakan mesin atau peralatan dan memar akibat benturan pada saat praktik. 


\section{Lingkungan Kerja}

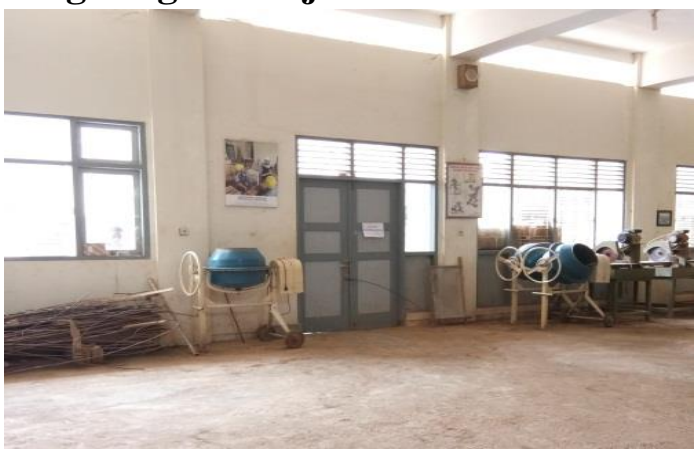

Gambar 3. Lingkungan Kerja

Lingkungan kerja di bengkel finishing bangunan SMK Negeri 2 Yogyakarta dari segi pencahayaan buatan, pencahayaan alami, dan ventilasi sudah memadai dan memenuhi standar untuk bangunan bengkel serta kebersihan tempat kerja juga terjaga.

\section{Peralatan Kerja}

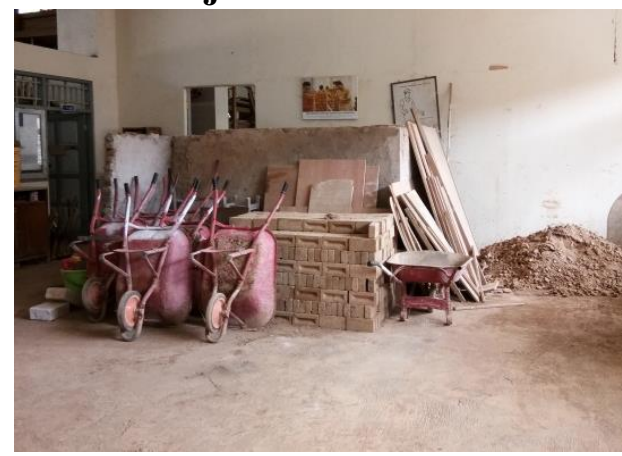

Gambar 4. Peralatan Kerja

Peralatan kerja yang tersedia di bengkel finishing bangunan jumlahnya sudah cukup namun kondisi mesin dan peralatan kerja ada beberapa yang sudah tidak layak pakai dan harus segera diganti tetapi dari pihak bengkel sudah mengajukan proposal ke sekolah untuk mengganti dengan alat yang baru dan letak mesin sudah cukup baik namun perlu dibenahi lagi agar peletakan mesin lebih tertata dengan rapi.

\section{Transaction (Proses)}

Tahapan ini memiliki indikator penerapan K3 dengan sub indikator yaitu pelatihan K3, penggunaan APD, sikap kerja, pengawasan, pencegahan dan penanggulangan, serta kesiapan keadaan darurat. Berikut adalah hasil penelitian objek dari indikator penerapan $\mathrm{K} 3$ :

\section{Pelatihan K3}

Pelatihan K3 di bengkel di lakukan pada awal semester tiap mata pelajaran selalu ada pengantar seperti pelatihan K3 untuk siswa dan guru menjelaskan dengan cara demontrasi didepan siswa.

\section{Penggunaan APD}

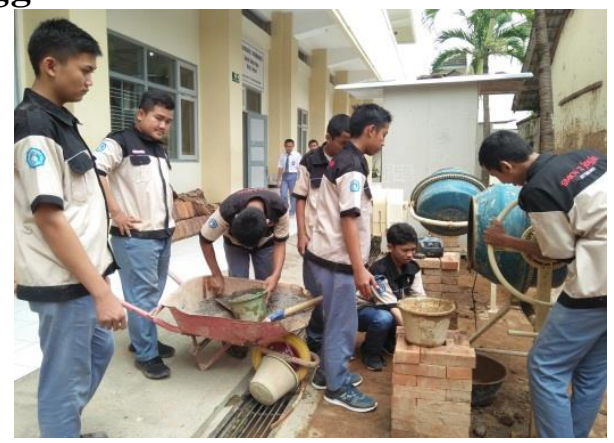

Gambar 5. Penggunaan APD

Penggunaan APD di bengkel cukup diterapkan oleh siswa pada saat praktik karena APD sangat penting untuk keselamatan dirinya sendiri maupun peralatan yang digunakan waktu praktik namun ada beberapa siswa yang kurang memperhatikan penggunaan APD. Guru biasanya menegur siswa jika tidak menggunakan APD sesuai dengan prosedur seperti wearpack, helm, pelindung mata, pelindung telinga, sarung tangan, dan sapatu boots. Konsekuensinya jika siswa tidak mengguakan APD disuruh lari memutari lapangan atau push up dan siswa disuruh pulang untuk mengambil wearpack atau meminjam ke kelas lain.

\section{Sikap Kerja}

Sikap siswa pada saat praktik cukup baik namun ada beberapa siswa yang kurang memperhatikan atau bercanda dan bergurau sendiri biasanya guru langsung menegur kemudian memperingatkan siswa agar memperhatikan dan lebih konsentrasi lagi dalam praktik, karena kalau pada saat 
praktik siswa tidak memperhatikan pekerjaannya akibatnya bisa fatal dan bisa terjadi kecelakaan kerja yang tidak diinginkan. Jika ada siswa yang kurang minat terhadap praktik finishing bangunan guru biasanya memberi motivasi agar siswa tersebut semangat dalam mengikuti praktik dan diharapkan bisa diterima dengan senang, sedangkan kalau ada siswa yang malas pada saat praktik guru biasanya menanyakan kenapa sebabnya dan kalau siswa tersebut ternyata malas karena lapar guru menyuruh siswa untuk makan terlebih dahulu dan karena disini praktik maka kondisi badan harus dijaga.

\section{Pengawas an}

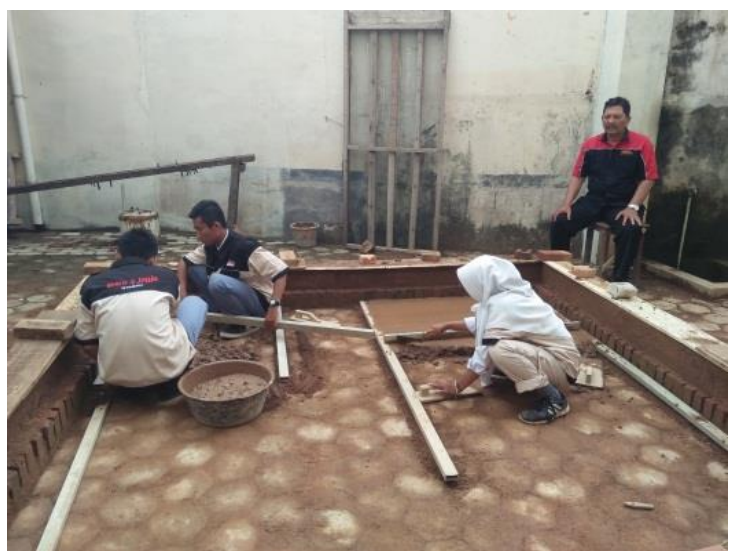

Gambar 6. Pengawasan

Pengawasan selalu dilakukan pada saat praktik dengan cara guru berkeliling mengecek pekerjaan siswa tersebut dan memperhatikan K3 dan kelengkapan APD yang digunakan kemudian guru akan menegurnya jika ada siswa yang tidak patut dengan K3.

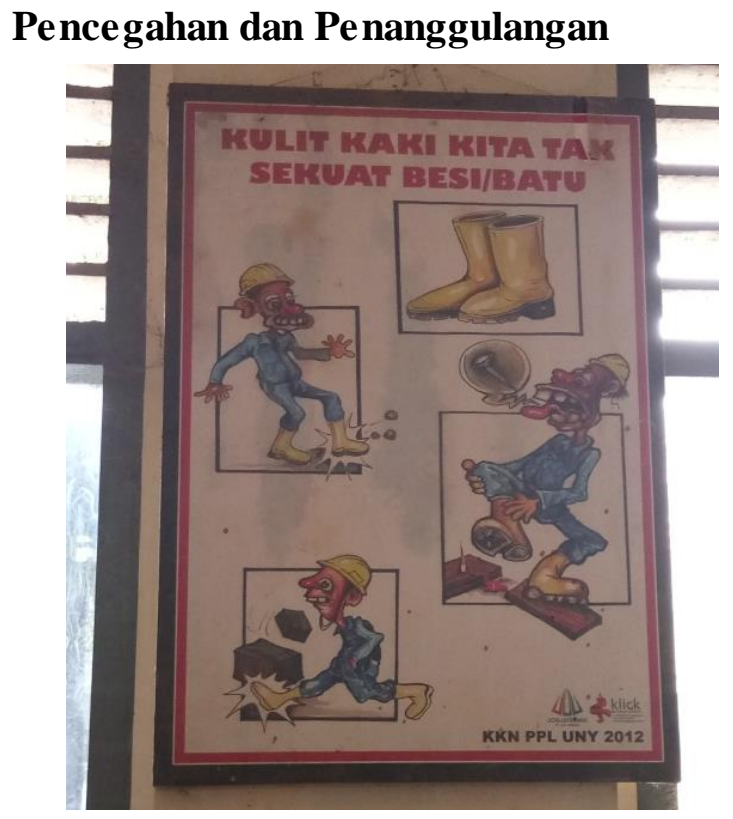

Gambar 7. Pencegahan dan Penanggulangan

Pencegahan dan penanggulangan terdapat di bengkel batu berupa poster yang tertempel didindiing maupun rambu-rambu larangan yang tertempel di mesin dan peneguran langsung dari guru atau teknisi jika ada siswa yang tidak mematuhi peraturan karena sebelum praktik terdapat briffing yang menjelaskan bahwa kelengkapan APD dan memperhatikan K3 itu sangat penting dilakukan pada saat praktik.

\section{Kesiapan Keadaan Darurat}

Kesiapan keadaan darurat yang berupa silabus dan jobsheet untuk panduan pada saat praktik sangat diperlukan karena salah satu pegangan atau pedoman guru dalam mengajar dan jika tidak ada silabus maka proses mengajar tidak berjalan dengan lancar serta jika siswa tidak mempunyai jobsheet akan kesulitan dalam menyelesaikan job yang diberikan oleh guru.

\section{Output}

Tahapan ini memiliki indikator pemantauan dan evaluasi kinerja K3 dengan sub indikator berupa dokumen evaluasi K3 . Berikut adalah hasil penelitian objek dari 
indikator pemantauan dan evaluasi kinerja

K3: (1) Pelaporan dan pencatatan kecelakaan kerja terdokumentasi dalam bentuk laporan sementara ketika ada siswa yang mengalami kecelakaan kerja kemudian laporan tersebut diserahkan kepada guru yang mengampu praktik tersebut. (2) Pemeliharaan sarana dan prasarana di bengkel cukup baik karena penggunaan alat dan mesin sesuai dengan fungsinya agar alat atau mesin yang digunakan tidak cepat rusak, begitupun dengan bengkel yang selalu dalam keadaan cukup baik karena selalu dirawat, dibersihkan, dan dirapikan sesuai dengan prosedur. (3) Pemantauan kesehatan dilakukan oleh guru pada saat praktik dilaksanakan dengan cara guru berjalan sambil mengecek pekerjaan siswa dan memantau siswa apakah sudah menggunakan APD yang sesuai dengan prosedur serta memantau apakah siswa tersebut dalam keadaan sehat atau sakit.

Hasil dari penelitian di SMK Negeri 2 Yogyakarta khususnya di penerapan dan pemahaman K3 pada praktik finishing bangunan akan dianalisis dalam bentuk tabel dan diagram lingkaran sebagai berikut.

Hasil penelitian menunjukkan bahwa dalam penerapan $\mathrm{K} 3$ untuk siswa yang belum menerapkan $\mathrm{K} 3$ sebanyak 4\% dan yang menerapkan K3 sebanyak 96\%. Pemahaman siswa menunjukkan bahwa ada siswa yang tidak paham dengan alat $\mathrm{P} 3 \mathrm{~K}$ apa saja yang disediakan di bengkel terdapat $9 \%$ siswa. Sedangkan yang menujukkan miskonsepsi $0 \%$ siswa dan siswa yang paham sebanyak $91 \%$ siswa.

Siswa yang belum paham terhadap cara mengidentifikasi bahaya dalam penggunaan mesin pada saat praktik terdapat $3 \%$ siswa. Sedangkan yang menujukkan miskonsepsi 9\% siswa dan siswa yang paham sebanyak $88 \%$ siswa. Pemahaman siswa mengenai jenis kecelakaan apa saja yang mungkin terjadi pada saat praktik di bengkel terdapat 3\% siswa yang belum paham. Sedangkan yang menujukkan miskonsepsi $33 \%$ siswa dan siswa yang paham sebanyak $64 \%$ siswa.

Untuk pemahaman siswa mengenai bagaimana cara siswa dalam menjaga kebersihan tempat kerja pada saat praktik tidak terdapat siswa yang belum paham. Sedangkan yang menujukkan miskonsepsi $37 \%$ siswa dan siswa yang paham sebanyak $63 \%$ siswa.

Pemahaman siswa tentang apa saja APD yang tersedia di bengkel dan konsekuensinya jika tidak menggunakan APD menunjukkan bahwa tidak ada siswa yang tidak paham. Sedangkan yang menujukkan miskonsepsi $24 \%$ siswa dan siswa yang paham sebanyak $76 \%$ siswa. Adapun mengenai penggunaan APD seperti wearpack, safety helmet, pelindung mata, pelindung telinga, pelindung tangan, safety shoes digunakan pada saat praktik apa maka tidak ada siswa yang tidak paham. Sedangkan yang menujukkan miskonsepsi $17 \%$ siswa dan siswa yang paham sebanyak $83 \%$ siswa.

Siswa yang tidak paham mengenai apakah setiap praktik ada pengawasan dari guru/ teknisi dan bagaimana bentuk pengawasan guru/teknisi dalam penerapan K3 pada praktik finishing bangunan terdapat $3 \%$ siswa. Sedangkan yang menujukkan miskonsepsi $21 \%$ siswa dan siswa yang paham sebanyak $76 \%$ siswa.

Selain itu ada siswa yang tidak paham mengenai jenis peringatan K3 apa saja yang terdapat di bengkel batu dan dalam bentuk apa peringatan $\mathrm{K} 3$ terdapat $6 \%$ siswa. Sedangkan yang menujukkan miskonsepsi $21 \%$ siswa dan siswa yang paham sebanyak $73 \%$ siswa. Tidak ada juga siswa yang tidak 
paham sebelum melaksanakan praktik apakah terdapat briffing terlebih dahulu dan mengapa harus ada briffing terdapat 0\% siswa. Sedangkan yang menujukkan miskonsepsi $18 \%$ siswa dan siswa yang paham sebanyak $82 \%$ siswa.

Sebanyak $3 \%$ siswa tidak paham mengenai bagaimana cara siswa dalam pemeliharaan tempat kerja setelah praktik. Sedangkan yang menujukkan miskonsepsi $12 \%$ siswa dan siswa yang paham sebanyak $85 \%$ siswa.

Demikian juga masih ada $3 \%$ siswa yang tidak paham menggunakan panduan apa siswa melaksanakan praktik finishing bangunan dan dengan cara apa guru menyampaikan pengantar praktik serta apakah dengan cara tersebut siswa sudah paham. Sedangkan yang menujukkan miskonsepsi 33\% siswa dan siswa yang paham sebanyak $64 \%$ siswa.

Hal yang menggembirakan adalah tidak ada siswa yang tidak paham tentang apakah terdapat pelaporan dan pencatatan kecelakaan kerja pada saat praktik dan dalam bentuk apa pelaporan dan pencatatan kecelakaan kerja yang diberikan kepada guru. Sedangkan yang menujukkan miskonsepsi $18 \%$ siswa dan siswa yang paham sebanyak $82 \%$ siswa.

Namun masih disayangkan terdapat $3 \%$ siswa yang tidak paham bagaimana cara siswa memelihara sarana dan prasarana di bengkel terdapat 3\% siswa. Sedangkan yang menujukkan miskonsepsi $9 \%$ siswa dan siswa yang paham sebanyak $88 \%$ siswa.

\section{SIMPULAN}

Berdasarkan penelitian, analisis, dan pembahasan hasil penelitian tentang Evaluasi Penerapan Keselamatan dan Kesehatan Kerja (K3) Pada Praktik
Finishing Bangunan Kelas XI Program Keahlian KGSP SMK Negeri 2 Yogyakarta yang telah diuraikan diatas maka peneliti dapat mengambil beberapa kesimpulan, yaitu:

Antecedents (input) dari penerapan $\mathrm{K} 3$ oleh guru pada praktik finishing bangunan dalam aspek kesiapan guru dan siswa sudah baik ditinjau dari penetapan dasar hukum dan perencanaan K3 sudah terlaksana. Antecedents (input) dari pemahaman K3 oleh siswa pada praktik finishing bangunan berjalan dengan baik dilihat dari persentase pemahaman perencanaan $\mathrm{K} 3$ dengan nilai tertinggi sebanyak $91 \%$ siswa dan terendah sebanyak $52 \%$ siswa.

Transaction (proses) dari penerapan $\mathrm{K} 3$ oleh guru pada praktik finishing bangunan telah berjalan dengan baik dilihat dari persentase penerapan K3 sebanyak 96\%. Transaction (proses) dari pemahaman K3 oleh siswa pada praktik finishing bangunan telah berjalan dengan baik dilihat dari persentase pemahaman penerapan K3 dengan nilai tertinggi sebanyak $85 \%$ siswa dan terendah sebanyak $64 \%$ siswa.

Output dari penerapan $\mathrm{K} 3$ oleh guru pada praktik finishing bangunan ditinjau dari hasil Pemantauan dan evaluasi kinerja K3 yang dicapai sudah baik. Output dari pemahaman K3 oleh siswa pada praktik finishing bangunan ditinjau dari hasil Pemantauan dan evaluasi kinerja K3 yang dicapai sudah baik berdasarkan dari persentase pemahaman hasil $\mathrm{K} 3$ dengan nilai tertinggi sebanyak $88 \%$ siswa dan terendah sebanyak $82 \%$ siswa.

\section{DAFTAR RUJUKAN}

Asrul., Rusydi Ananda., \& Rosnita. (2014). Evaluasi Pembelajaran. Bandung: Citapustaka Media.

Astiti K. A. (2017). Evaluasi Pembelajaran. Yogyakarta: CV. Andi Offset. 
Buntarto. (2015). Panduan Praktis Keselamatan \& Kesehatan Kerja untuk industri. Yogyakarta: Pustaka Baru.

Irzal M. (2016). Dasar-Dasar Kesehatan dan Keselamatan Kerja. Jakarta: Kencana.

Kuswana W. S. (2014). ERGONOMI dan K3 Kesehatan Keselamatan Kerja. Bandung: PT Remaja Rosdakarya.

Kuswana W. S. (2015). Mencegah Kecelakaan Kerja. Bandung: PT Remaja Rosdakarya.

Peraturan Menteri Tenaga Kerja Republik Indonesia No. PER.03/MEN/1998 tentang Cara Pelaporan Dan Pemeriksaan Kecelakaan.

Ramli S. (2010). Sistem Manajemen Keselamatan dan Kesehatan Kerja OHSAS 18001. Jakarta: Dian Rakyat.

Sadewa Aji W., \& Nur Kholis. (2015). Evaluasi Program Praktik Kerja Industri pada Bidang Keahlian Teknik Instalasi Tenaga Listrik di SMK Swasta Se-Kabupaten Sleman. Jurnal UNY. 3(V). Hlm. 71-78.

Undang Undang No. 1 Tahun 1970 tentang Keselamatan Kerja.

Undang Undang No. 8 Tahun 1999 tentang Perlindungan Konsumen.

Undang Undang No. 13 Tahun 2003 tentang Ketenagakerjaan.

Undang Undang No. 20 Tahun 2003 tentang Sistem Pendidikan Nasional.
Wirawan. (2011). Evaluasi Teori, Model, Standar, Aplikasi dan Profesi. Jakarta: PT. Raja Grafindo Persada.

Wirawan. (2012). Evaluasi Teori, Model, Standar, Aplikasi, dan Profesi. Depok: Raja Grafindo Persada.

Yunanda M. (2009). Evaluasi Pendidikan. Jakarta: Balai Pustaka.

Zainal Arifin. (2010). Evaluasi Pembelajaran. Bandung: Remaja Rosdakarya. 